\title{
Vaccines Mandates, Covid Tests, Robert F. Kennedy Jr.'s Book on Fauci, and Resolving Related Family Issues
}

\section{Benjamin $\mathrm{E}^{*}$}

Psychology Department, Capella University, USA

*Corresponding author: Elliot Benjamin, Psychology Department, Capella University, Minneapolis, MN, USA, Email: ben496@prexar.com

\section{Review Article}

Volume 6 Issue 1

Received Date: January 10, 2022

Published Date: March 01, 2022

DOI: $10.23880 / \mathrm{mhrij}-16000165$

\section{Abstract}

In this article the author discusses the efforts he has made to preserve his important relationship with a family member, working through issues related to vaccine mandates, Covid tests, and the reading of Robert F. Kennedy Jr's book The Real Anthony Fauci. The author describes how significant issues in his family relationship have gotten resolved through a mutual give-and-take with his family member with openness to communication and compromise on both of their parts, facilitated by the author's willingness to engage in reading Kennedy's book on Fauci that challenged many of his initial beliefs. However, the author was also able to convey concerns that he had about Kennedy's book to his family member, resulting in an authentic communication between them and a preservation of their relationship. Finally, the author relates his experiences to the empathy and authenticity core principles of humanistic psychology, with a focus on Kirk Schneider's experiential democracy work to try to heal the political polarization divide in the United States.

Keywords: Vaccine Mandates; Covid Tests; Fauci; Humanistic Psychology; Experiential Democracy

\section{Introduction}

I have previously described my efforts to maintain a family relationship that is very important to me, and that was in danger of falling apart due to our opposing views about vaccines. The way that I was able to resolve the impasse of getting together in person with this family member was by means of a compromise whereby my unvaccinated family member agreed to get Covid tests as a condition for us seeing each other, and promised that he would be cooperative about wearing masks and social distancing as much as I ask him $[1,2]$. Since then, my family member had also agreed to get an antibodies test, as I said that it would be helpful to me to know if he had built up antibodies to the virus by means of having had a symptomless case of Covid (1). These are all good things that I am very thankful for, and the plan is for us to work out the logistics for seeing each other sometime in the spring or summer of 2022, after I get my next booster shot (2). Furthermore, this resolution led to me stretching myself more than I thought I would be able to do, which involved my reading the book he asked me to read: a massively referenced book by Robert F. Kennedy Jr. [3] entitled The Real Anthony Fauci: Bill Gates, Big Pharma, and the Global War on Democracy and Public Health.

Anthony Fauci was something of a hero to me, as he has been to many Americans. He represented a degree of sanity and ethics and scientific intelligence during the challenging ordeal of the 4 years of President Trump [4]. Thus reading nearly 500 pages with over 2,000 references of a book by a prominent anti-vaxxer who was wholly dedicated to tearing down Fauci's reputation was not something that I wanted to engage in. However, my family member was passionate in his anger towards Fauci, and I knew that I had to honor his request in order to keep the lines of communication open between us. I therefore ordered the book and braced myself 


\section{Mental Health \& Human Resilience International Journal}

for the unpleasant undertaking. But to my great surprise, I found that I actually liked the book. Kennedy RF [3] has made a tour de force case for his substantial criticism of the 50 year career of Anthony Fauci, and has given harrowing descriptions of historical events surrounding Fauci in his role as director of the National Institute of Allergy and Infectious Diseases (NIAID) for the past 37 years. This included, according to Kennedy RF [3], Fauci's suppression of promising low cost therapeutic treatments for AIDS and Covid, his promotion of expensive detrimental treatments for these diseases, his unethical manipulation of what was funded and not funded in regard to various potential anti-virus drugs, his promotion of vaccines at the expense of alternative or additional community-based inexpensive therapeutic treatments, his collusion with big pharmaceutical companies (which has commonly been referred to as Big Pharma) to control the findings of his scientific drug researchers as well as their publications and results, and his overseeing a very harmful AIDS drug treatment project in Africa, which was subsequently extended to multiple countries all over the world. Although I will give some brief descriptions below of Kennedy Jr.'s [3] book, my purpose in this article is not to give a detailed description of the book, as my present article is focused on the relationship of my reading this book to resolve the issues between myself and my family member regarding vaccine mandates and Covid tests (3). Perhaps others may find my descriptions of this resolution to be helpful in their own similar challenges with family members.

\section{Reading Kennedy's Book and Resolving My Related Family Issues}

If I had heard someone state my long sentence above about Fauci's various promotions, suppressions, unethical manipulations, and collusions from Kennedy Jr.'s [3] perspective, I may have labelled this person as having been indoctrinated into the anti-vaccine/anti-Fauci/antigovernment conspiracy, and I may have even associated this person with the notorious January 6th insurrectionists. But lo and behold, this person is me! I am the one who promoted this statement denouncing Fauci, so what does this mean? Have I lost my mind, or capitulated my rational thinking to preserve the relationship with my family member? Again, it is not my purpose in this article to give detailed explanations of what Kennedy RF [3] has described in relation to Fauci (3). However, I will say clearly here that I think my above statement that describes Kennedy Jr.'s [3] perspective on Fauci may be essentially accurate, and I say this in spite of some serious flaws in Kennedy Jr.'s (3) claims about Covid vaccines, masks, and social distancing, as I describe below. Readers would have to judge for themselves the merit of Kennedy Jr.'s [3] take-down of Fauci, but I must admit that my own hero perspective of Fauci no longer applies. I have learned things about Fauci that I did not want to learn, and that I wish were not true. I have searched for defences in support of Fauci against Kennedy Jr.'s [3] accusations, but I have not found anything substantial to refute most of Kennedy Jr.'s [3] claims. In spite of the serious flaws in Kennedy Jr.'s [3] depictions about vaccines, masks, and social distancing, and his inclusion of faulty research to promote his belief that ivermectin is a beneficial treatment for Covid, I cannot argue with the bulk of his devastating portrayal of Fauci's destructive impact upon public health over the course of many years $[3,4]$.

Be that as it may, what my focus is on in this present article is the following question: What impact has my reading of Kennedy Jr.'s [3] book had on resolving the difficult issues in the relationship with my family member? To begin with, given my family member's openness to my requests about his getting tested for both Covid and antibodies (1), and his willingness to wear masks and practice social distancing as much as I ask him to, I felt that it was only fair that I reciprocated by, in addition to agreeing to get together in person with him, reading the book that he asked me to read. And as it turned out, I was able to genuinely share with my family member the repulsion that I felt from reading about all the horrors that Fauci purportedly committed to promote his vaccines and drug treatments for AIDS for almost 4 decades. Of course these horrors, in particular untold numbers of unnecessary deaths and serious illnesses, should be investigated in a fair and impartial way, preferably by a United States Congressional hearing. But I must say that the historical data appears to me be to be factual and easily verified, and at the very least it brings up alarming questions in my mind about the high level of praise and ethical virtues that have been bestowed upon Anthony Fauci [3,5], and this naturally leads me to question both the ethics and safety of Fauci's current leadership in regard to his decisions and actions regarding our present coronavirus pandemic. I still believe that the benefits outweigh the detriments for getting vaccinated against Covid [6,7] but it also makes me more sympathetic to why someone may not trust what the government says about vaccine safety and adverse reactions, and various related matters.

At any rate, my reading this book turned out to be an enormous bridge to overcome the threat of alienation between me and my family member, although this could very well have backfired if my reaction to the book had been different. I stretched myself enormously in this undertaking, knowing that there was a big risk that I could end up feeling even more alienated from my family member after reading a bunch of unfounded ad hominem "anti-vaxxer" attacks on someone whom I considered to be a courageous, intelligent, ethical, renowned, and dedicated scientist. I took the leap of faith in the interest of being genuine and letting the chips fall where they may, and now I am faced with a miniature version 


\section{Mental Health \& Human Resilience International Journal}

of what my family member is overwhelmingly experiencing, which is how to navigate my new awareness and concerns when relating to people who put Fauci on a pedestal as the most respected medical doctor in the United States.

But at the same time, as I mentioned above, I found a number of flaws in Kennedy Jr.'s [3] book that were very concerning to me $(3,4)$ and it was essential that I was able to communicate my concerns to my family member and feel that I was listened to and understood and taken seriously, at least to some extent. This essentially happened, though with a good deal of give-and-take back and forth communications between us, and I had to accept that although my concerns were acknowledged as at least somewhat legitimate, they were also minimized with a justification that they were relatively minor and that Kennedy RF [3] understandingly went a bit too far in some of his statements and research, due to the immensity of the corruption and tragedies that he was writing about in such enormous scope. However, I will state here that I don't think my concerns were at all minimal, as they included Kennedy Jr's [3] biased portrayal of death spikes being caused by vaccines in a number of different countries, his ignoring a complete lack of statistical significance when conveying differences in number of deaths between vaccinated and unvaccinated people in the Pfizer Covid trial that was used for full FDA approval, his unfounded statements that neither wearing masks nor social distancing have been beneficial in reducing Covid infections and deaths, and his use of faulty research to promote his belief that ivermectin is a beneficial treatment for Covid $(3,4)$. Nevertheless, what is most important to me is that my family member and I were able to have these communications, and that we were able to speak our minds and agree on the essence of what the book has conveyed, though disagreeing on the importance of some of the book's agreed upon flaws. And I believe that these communications with my family member that I have engaged in, inclusive of our agreement about allowing for Covid tests as an alternative to vaccine mandates, and utilizing, Covid tests, wearing masks, and social distancing as requirements for us to see each other, as well as my openness to read a book he asked me to read that I very much did not want to read but ended up reading and finding a great deal of value from, is directly related to both the core principles of humanistic psychology and Kirk Schneider's experiential democracy work, that I will describe next.

\section{Humanistic Psychology, Experiential Democracy, and Resolving Difficult Family Issues}

The core principles of humanistic psychology are based on empathy and authenticity in human relationships
$[8,9]$. These core principles have been put into practice in the midst of the current extensive political polarization in the United States through Schneider's [10] experiential democracy work, in which people who have polarized opposite political perspectives sit with each other and respectfully listen to and acknowledge each other's feelings and viewpoints. I believe that what I am experiencing and advocating for in regard to resolving difficult family issues is directly related to Schneider's experiential democracy work. The people involved are family members and the communication may not be in-person, but the aspect of "respectfully listening to and acknowledging each other's feelings and viewpoints" is very much what I am currently experiencing in the communications with my family member in regard to vaccine mandates and Covid testing, as I have described above. My family member has respectfully listened to and acknowledged my safety needs with the result that he has agreed to get Covid tests as a condition for us seeing each other. And I have respectfully listened to and acknowledged my family member's existential need to not be forced into getting the Covid vaccine, for any reason whatsoever. Furthermore, I have stretched myself to read the book that my family member asked me to read: Kennedy Jr.'s [3] book on Fauci. And I must say that reading this book has increased my understanding of my family member's decision to not get the Covid vaccine. I have previously written about the legitimate concerns that a number of authors have conveyed about various disturbing factors in regard to vaccines, inclusive of the biased vaccine approval process, the unethical practices of the big pharmaceutical companies that make the vaccines, the occurrence of possible detrimental physiological consequences from being injected with vaccines, and the various environmental hazards that have been ignored for the purpose of promoting vaccines [5,14]. However, in spite of these disturbing factors, I concluded that the benefits outweighed the detriments for getting vaccinated against Covid [5,14]. Reading Kennedy Jr.'s [3] book has not caused me to change my mind about this, but I must admit that it has significantly added to my concerns about the Covid vaccine.

Kennedy Jr's [3] book was an eye-opener for me in regard to the checkered 50 year career of questionable ethics and deadly consequences of Anthony Fauci's tremendous power and influence to promote the spread of vaccines throughout the world, specifically trying to come up with a vaccine for AIDS that Kennedy RF [3] has argued has resulted in catastrophic consequences. Furthermore, I have learned about the unprecedented extensive power and influence of billionaire Bill Gates as he teamed up with Fauci to make vaccines the "one and only" health initiative to solve the world's health problems, ignoring more natural therapeutic alternatives and any kind of environmental project that could increase people's living conditions. I have also become more knowledgeable about the apparent horrific lack of scientific 


\section{Mental Health \& Human Resilience International Journal}

integrity and lack of compassion in hiding disastrous and deadly results of adverse vaccine consequences, as well as the influence that Fauci in particular has had on a number of United States presidents to fund and promote questionable vaccines in third world countries. Of course all of Kennedy Jr.'s [3] claims should be carefully examined and not taken at face value, but his historical use of public data and statements from various medical officials who were involved in high level government operations is certainly something that should not be ignored, and I believe it warrants a Congressional hearing.

Kennedy RF [3] conveyed the transition from unethical AIDS testing of vaccines over many years to our current testing of the Covid vaccine, which followed extensive "germ games" simulations, with the same high level governmental administrators involved whom he described in terms that are very alarming, with Fauci at the top of the list, promoted big time by Bill Gates. Thus, although I still believe that the benefits outweigh the detriments for getting the Covid vaccine, reading Kennedy Jr.'s [3] book has most definitely made me more understanding of my family member's perspective and his reasons for deciding not to get vaccinated. And my understanding of this is going a long way in healing the divide between us, even if we still do not agree about the actual vaccination issue itself. It is experiential democracy played out on the family turf, and I think it is a tremendously important and timely way to put into practice the core principles of humanistic psychology.

\section{Conclusion}

In conclusion, I am very thankful that I have been able to find a way to bridge the potential polarization and alienation that was threatening the relationship between me and my family member. This bridging the gap required both of us to stretch ourselves beyond what we felt comfortable with in order to see each other again, but we agreed to do so out of our caring for each other, to preserve our relationship. This subsequently led me to stretch myself even further, to read a book that my family member asked me to read that was completely antithetical to everything I believed in regarding vaccines and the trustworthy and respectful image that I had of Anthony Fauci. But much to my surprise, I resonated with a great deal of what the book conveyed, in spite of what I viewed as serious flaws in the book $(3,4)$ and the result has been that it enabled the relationship between myself and my family member to become closer and less threatened by the polarization that many people are concerned may destroy our country $[11,12]$. The efforts that I have put into this process of engagement are related to Schneider's [10] experiential democracy project, but with a focus upon the relationship between family members. It may be worthwhile for others who find themselves in a similar potentially polarized family relationship to explore some of the ideas that I have described here, for the purpose of regaining the closeness in their family relationship through reducing the alienation between themselves and their family members.

\section{Notes}

1. I subsequently decided to drop my antibodies test requirement, based upon the information that my family member conveyed to me about antibodies testing not being a reliable indication of possible immunity from Covid.

2. Based upon recent research that conveys only a minimal increase in immunity to the Omicron Covid variant from a second booster shot, I may not wait until I receive a second booster shot before getting together in person with my family member [13].

3. See Benjamin E [6,7] for my more extensive reviews of Kennedy Jr.'s [3] book.

4. Some examples of these serious flaws are as follows: Kennedy RF [3] presented graphs for a number of countries that displayed a sharp increase in deaths after vaccination, implying that the vaccines caused the deaths. However, some of these countries received their vaccination around Christmastime or during the winter, such as in Ireland, which would certainly explain the sudden increase in deaths. There is also the factor of more time passing leading to more people getting infected and more deaths, and the sharp decrease in deaths that soon followed could very well be attributed to the vaccine.

Kennedy RF [3] considered it to be a major concern that in the Pfizer Covid trial that was used for complete FDA approval there were 14 deaths in the unvaccinated group and 20 deaths in the vaccinated group, stating that there were nearly $150 \%$ as many deaths in the vaccinated group compared to the unvaccinated group. However, the difference in these deaths numbers is not statistically significant (using a standard Chi-Squares test) at any level of significance that is ever used in professional research studies. Thus Kennedy Jr's [3] portrayal of this is both unsubstantial and misleading. Kennedy RF [3] claimed that neither wearing masks nor social distancing has been effective against getting infected by Covid, but he gave very little evidence to back up these claims, and he never included any of the extensive research that supports the efficacy of wearing masks or social distancing. Similarly, Kennedy RF [3] stated that the number of deaths from Covid may be less than what has been reported, but he did not give evidence to back up his claim, and focused on the fact that the prediction of 2 million deaths during the first year of Covid did not occur. However, Kennedy RF [3] did not acknowledge the 


\section{Mental Health \& Human Resilience International Journal}

fact that unlike the other pandemics thus far in the 21st century that were expected to have far more deaths than occurred, there have been an enormous number of Covid deaths, currently over 900,000 .

Kennedy RF [3] ended his book by emphasizing how Covid data from Israel shows that there is no significant difference in transmission of Covid between vaccinated and unvaccinated people, but neglected to include research that shows unvaccinated people or more likely to get infected with Covid than vaccinated people to begin with, thereby demonstrating that vaccination may very well reduce the likelihood of infecting others when this is taken into account. Kennedy RF [3] also made no mention of the solidly established research which shows that Covid symptoms, hospitalizations, and deaths are much more prominent in unvaccinated people compared to vaccinated people. And finally, Kennedy RF [3] made a major point to end his book by citing the September, 2021 data in Israel that conveys $60 \%$ of people in severe and critical condition, and $45 \%$ of people who died, were doubly vaccinated. However, Kennedy RF [3] did not include the fact that at that time, nearly $80 \%$ of Israeli adults were doubly vaccinated, which when taken into account actually may very well demonstrate the effectiveness of the vaccine since the percentages of people in severe and critical condition, and who died, were significantly less than the percentage of adults who were doubly vaccinated.

To forcefully convey his belief that ivermectin is a beneficial treatment for Covid, Kennedy RF [3] strongly promoted faulty research. See Benjamin E [7] for a description of the related issues and Kennedy Jr.'s [3] problematic ivermectin promotion.

5. Some of the concerns about Fauci that stand out for me are as follows: According to Kennedy RF [3], Fauci's suppression and mis-characterization of two potentially beneficial drugs to treat Covid: ivermectin and hydroxychlororoquine, along with his promotion of a detrimental Covid treatment drug: remdesivir. However, although I have concerns about this, I have not yet investigated Kennedy Jr.'s [3] references to support his claims about hydroxychloroquine and remdesivir, and there are problematic issues in regard to Kennedy Jr's [3] use of faulty research to promote his claims about ivermectin. But Kennedy RF [3] made a very strong case to show a strong unethical connection of Fauci, supported by Bill Gates, to Big Pharma, with the disastrous consequence of numerous deaths in Africa, inclusive of many children, that apparently were caused by unexpected negative consequences of the AIDS vaccines used as trials.
According to Kennedy RF [3], Fauci'scontinued promotion of vaccines that had detrimental consequences, inclusive of numerous deaths, while taking punitive actions towards reputable researchers who criticized these vaccines, and not addressing the dangers to the health of millions of people in third world countries who were used in these vaccine drug trials.

According to Kennedy RF [3], Fauci's complete focus upon vaccines in Africa and other third world countries, buttressed by the immense financial and promotional support of Bill Gates, at the expense of actions to improve the day-to-day health and living conditions of people in these countries.

6. See Benjamin E $[5,14]$ for my previous critiques of a number of anti-vaccination and germ theory denial authors, along with my rationale for why I concluded that the benefits outweigh the detriments for receiving the Covid vaccine. However, although I acknowledged the possible negative consequences of vaccines in these articles, I must admit that Kennedy Jr's [3] book has brought these possible negative consequences to a whole new level for me. I still believe that the benefits outweigh the detriments for receiving the Covid vaccine, but reading Kennedy Jr's [3] book has given me more of an understanding and appreciation of why my family member has been so adamant in refusing to get vaccinated against Covid. As my family member has conveyed to me, various research studies have demonstrated that factors such as living an active and healthy lifestyle, inclusive of nutrition and exercise and not smoking, are significant variables to take into account when determining the danger of getting infected by Covid.

7. The first part of my four-part article series To Get Vaccinated or Not to Get Vaccinated includes links to the other three parts of this article series.

\section{References}

1. Benjamin E (2021) On vaccine mandates: A personal integrative perspective.

2. Benjamin E (2021) Vaccine mandates, Covid tests, and humanistic psychology. Integral World.

3. Kennedy RF (2021) The real Anthony Fauci: Bill Gates, Big Pharma, and the global war on democracy and public health. Children's Health Defense.

4. Benjamin E (2020) Studies of social media addiction, cult indoctrination, and the coronavirus pandemic; all in relation to the Trump presidency. In: Kahlde BK, et al. (Eds.), Selected Topics in Humanities and Social Sciences, BP International 5: 135-147. 
5. Benjamin E (2021) Germ theory denial, anti-vaccination, and Covid-19. Integral World.

6. Benjamin E (2022) Anthony Fauci: Hero or villain?. Integral World.

7. Benjamin E (2022) Is Ivermectin an efective treatment for Covid? Integral World.

8. Rogers CR (1961) On becoming a person: A therapist's view of psychotherapy. Houghton Mifflin.

9. Schneider KJ (2015) Rediscovering awe: A new front in humanistic psychology, psychotherapy, and society. In: Schneider KJ, et al. (Eds.), The Handbook of Humanistic Psychology: Theory, Research, and Practice, Sage Publications, pp: 73-81.

10. Schneider KJ (2020) The depolarizing of America: A guidebook for social healing. University Professors Press.

11. Kagan R (2021) Opinion: Our constitutional crisis is already here. The Washington Post.

12. Tribe LH (2021) The risk of a coup in the next US election is greater now than it ever was under Trump. The Guardian.

13. Federman J (2022) $4^{\text {th }}$ COVID-19 vaccine dose less effective against Omicron, Israel study shows. Global News.

14. Benjamin E (2021) COVID: To get vaccinated or not to get vaccinated: Stimulated by a sociologist's scholarly anti-vaccination book. 